\title{
Criminal Careers and Demographic Outcomes: An Introduction to the Special Issue
}

\author{
Catrien Bijleveld \\ Mioara Zoutewelle-Terovan \\ Doreen Huschek \\ Aart Cornelis Liefbroer
}

Criminologists have become increasingly interested in the influence of demographic behaviors, like entry into marriage (Sampson, Laub \& Wimer, 2006; Bersani, Laub \& Nieuwbeerta, 2009), entry into parenthood (Giordano, Cernkovich, \& Rudolph, 2002; Monsbakken, Lyngstad \& Skardhamar 2013), and union dissolution (Farrington \& West, 1995; Blokland \& Nieuwbeerta, 2005), on criminal behaviors. A host of studies have shown that - at least among men - entry into marriage and entry into parenthood lead to a reduction in criminal offending, whereas divorce leads to an increase in offending (for an overview see Zoutewelle-Terovan et al., 2014).

Much less attention has been paid to the opposite effects, namely the influences of criminal offending on behaviors related to the key demographic processes of fertility, nuptiality and mortality. The neglect of this topic by demographers is somehow surprising. Criminal behavior is an important marker of social disadvantage, and a topic of interest for many demographers is to understand social differentials in demographic behavior. Moreover, life course demographers are also interested in understanding how demographic trajectories are influenced by events and careers in parallel life domains (Willekens, 1991), and the criminal career constitutes an interesting example of such a 'parallel career'. One of the reasons why demographers have often steered away from studying the influence of criminal engagement on demographic behavior is because they lack access to the type of detailed data on criminal careers that is needed to study this issue. From the criminology perspective, access to data is less problematic. However, it seems that criminologists were generally interested in analyzing criminal behavior as an outcome, thus defining criminal engagement as a dependent rather than an independent variable. Probably the best way to answer these questions is by developing interdisciplinary collaboration between criminologists and demographers, but such collaboration is still very rare.

This 'state of affairs' led the Netherlands Institute for the Study of Crime and Law Enforcement (NSCR), the Vrije Universiteit Amsterdam (VU Amsterdam) and the Netherlands Interdisciplinary Demographic Institute (NIDI) to organize a series of international workshops to study the influence of criminal behavior on a number of key demographic processes. In these workshops (held at the VU Amsterdam and NSCR in February and December 2012), criminologists and demographers from both sides of the Atlantic met to present and discuss papers on these rare topics. This special issue of Advances in Life Course Research is the final product of these workshops. It contains a set of papers that aim to ascertain whether criminal behavior influences patterns of union formation, union dissolution, parenthood, injury and mortality. In these papers, a 
particular attention is given to issues of causality or spuriousness. In analyzing the relationships between criminal careers and demographic outcomes, both intragenerational and inter-generational influences are considered. Moreover, these articles aim to understand whether the patterns differ between men and women, and whether they vary across different societal contexts.

Before we discuss how the articles included in this special issue contribute to the literature, we will briefly outline the different mechanisms through which criminal behaviors and demographic behaviors may be related.

\section{A theoretical model}

When theorizing the relationship between criminal and demographic events (even if one is mainly interested in the unidirectional influence of criminal offending on demographic events), it is imperative to take the bidirectional nature of this relationship into account. On the one hand, offending influences demographic behaviors. For instance, men who offend, and especially men who engage more often in criminal acts, may be seen as unattractive marriage partners (Sampson, Laub \& Wimer, 2006). In addition, marriages in which the partners is violent are more likely to lead to divorce/separation (Paternoster \& Iovanni, 1989). On the other hand, demographic events also affect people's propensity to engage in crime. The most often cited example is the 'good marriage effect', namely those men who conclude satisfying marriages tend to offend less or even engage in a law-abiding life-style (Laub, Nagin \& Sampson, 1998). These examples show that the association between marriage and crime is bidirectional.

Both mechanisms mentioned above describe an intra-generational effect: offending status affects marriage chances, and marital status affects offending chances. However, inter-generational effects can be envisaged as well. For instance, men and women born in 'criminal families' have more disturbed family pathways (Huschek \& Bijleveld, 2011). Their marriage chances may be reduced because criminal behavior in their family of origin signals negative traits such as (domestic) violence or a higher risk of poverty. Effects crossing generations might be observed also when studying offending as an outcome variable. For instance, parental divorce may place children at greater risk of offending. Unfortunately, these inter-generational effects occurring across the two domains (offending and demographics) are still understudied.

Although intra- and inter-generational effects are often considered separately, the effects of criminal offending on demographic behaviors may represent the joint result of inter-generational continuities in offending and demographic behaviors on the one hand, and intra-generational influences on the other hand. For instance, parents who engage in crime may 'transmit' their propensity to offend to their children, and the resulting criminal behavior of the children themselves may be the direct cause of their limited marriage or union formation chances. In that case, the seemingly 'direct' intergenerational crossdomain association may actually be a composite of two different mechanisms. From a different perspective, associations between offending and demographic outcomes in families may be entirely spurious, as both offending and demographic outcomes could be 
explained by underlying characteristics such as poverty, neighborhood disadvantage and intelligence, which may be transmitted inter-generationally as well.

The mechanisms outlined above are summarized in Figure 1. The arrows denoted as A depict the influence of offending on demographic transitions and statuses, intragenerationally. The arrows denoted as $\mathrm{A}^{\prime}$ depict the influence of demographic transition and statuses, intra-generationally, on offending. Similar intra-generational relationships hold for both parents and their children. Some of these relationships are denoted by dotted arrows in Figure 1, as they are not studied in the papers contained in this special issue. The arrow $B$ depicts the inter-generational influence of crime on demographic outcomes, and $B^{\prime}$ the inter-generational influence of demographic outcomes on criminal outcomes. Arrows $C$ and $D$ depict the intergenerational transmission of some specific behaviors (criminal offending or demographic behavior). For clarity of explanation, this model includes only relationships between criminal and demographic behaviors across two generations, and does not explain other relevant characteristics of deprivation that can also influence this relationship (e.g. socio-economic status, poverty, neighborhood disadvantage). However, the studies included in this special issue include such characteristics in the actual empirical model as they are important for several reasons: (a) they could demonstrate that the effects of criminal behavior on demographic behavior are spurious; (b) they might reveal that these effects are mediated by other aspects of deprivation; (c) they might show that these effects are moderated by other aspects of deprivation.

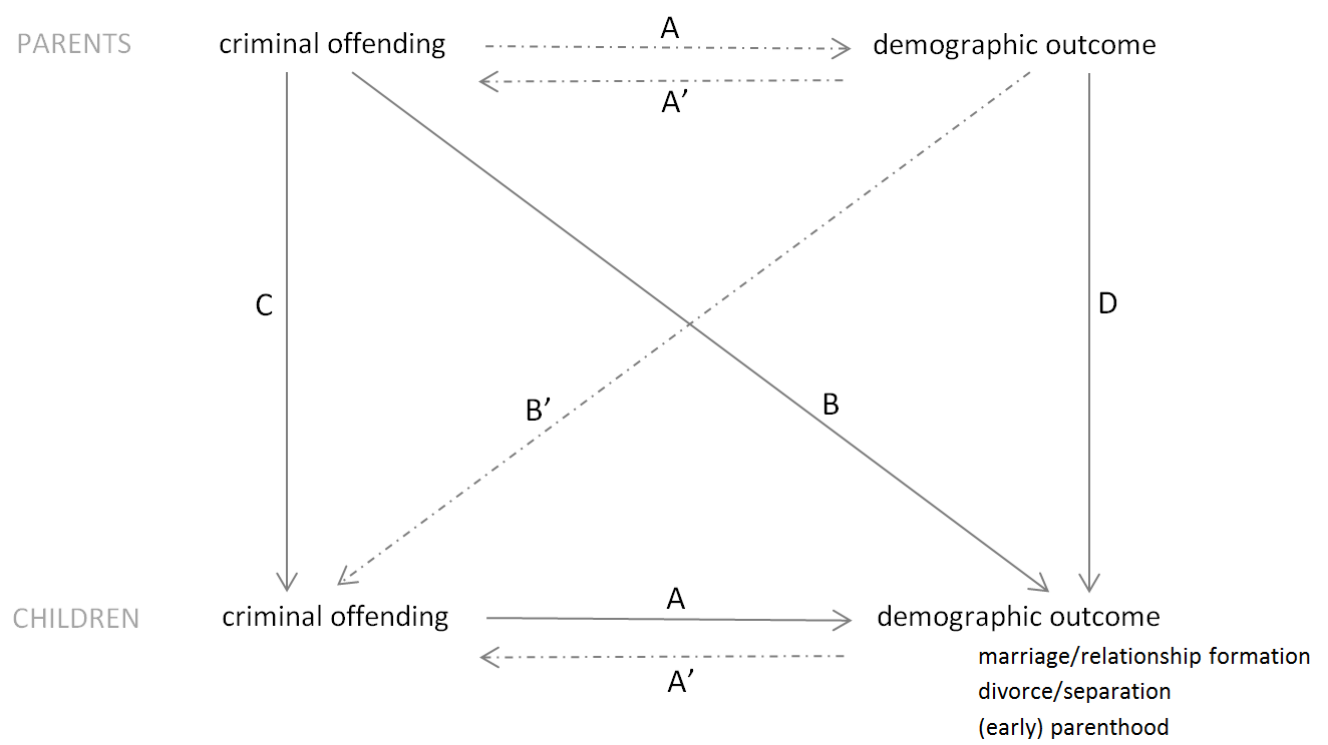

Figure 1. Possible relationships between offending and demographic outcomes.

The direction and strength of the relationships between criminal and demographic outcomes may depend on gender, historical or societal context, type of offending, and type of demographic behavior. For example, men and women may experience differently the negative influences of their own - or their parents' - criminal behavior. Because men are generally expected to be the main breadwinners, they might be more rigorously 
evaluated for family formation and criminal engagement, which may pose problems on the marriage or partnership formation market. Historical or societal context may matter, as well as the rules for prosecution of offending and the stigma attached to it may differ between historical periods and between societies. The effects of offending on demographic behaviors are probably stronger in societies where offending is highly stigmatized than in societies where stigma is relatively weak. Type of offending might also matter, as specific types of crimes may signal specific configurations of risk factors. For instance, violent offending may signal a high risk of domestic victimization whereas property offending might even on the contrary be regarded as a 'useful' supplement to the family income. If so, both types of offending may have very different influences on a person's family formation prospects. Finally, the type of demographic event should be considered as well because some events are 'easier to escape' than others, and some are more normatively endorsed than others (Liefbroer \& Billari 2010). For instance, offending may have stronger effects on marriage than on unmarried cohabitation, as the latter behavior is deemed to be more transient than marriage, and, thus, potential partners of criminal individuals may be more reluctant to marry a criminal partner than to cohabit with one.

\section{Content of this special issue}

This special issue brings together a set of papers that investigate the offendingdemography nexus by focusing on multiple types of demographic outcomes (union formation, union dissolution, parenthood, serious injury and mortality), and on different aspects of criminal behavior (prevalence, frequency and type of offending). These papers analyze intra-generational as well as inter-generational effects. They cover different historical periods (from the 1930s to the current day), and use different types of data (police records or convictions) and sampling strategy (high-risk or population based).

This subsection contains a summary of the papers published in the issue. Both the summary and the order of the papers in this special issue roughly follow the most common order in which demographic events occur in an individual's life course. We start with research on union formation and union dissolution, continue with parenthood, and end with injury and mortality.

Marriage outcomes are studied by Lyngstad and Skardhamar (2015), Besemer, Farrington and Theobald (2016), Schoon and Mullin (2016) and Thornberry et al. (2015). Generally, these studies find that crime (in adolescence and later life) is not related to the overall likelihood that someone enters a marital union. Rather, crime is related to the timing of entry into marriage. Specifically, criminal involvement leads to an earlier transition to marriage in both Norway and the UK (Lyngstad \& Skardhamar 2015; Schoon \& Mullin 2016). However, these results seem to hold only for adult behaviors, as adolescent risky behaviors (including crime) have no effect on early marriage in a US sample (Thornberry et al. 2015).

Other studies investigate relationship formation in a broader sense, by including married, cohabiting and non-cohabiting relationships, as well as relationship break-up. Thornberry et al. (2015) find that adolescent risky behaviors (including crime) are not 
related to what they call phrased stable relationships (cohabitation and marriage) for neither men nor women, but that serious delinquency increase the risk of early cohabitation for men. However, as Zoutewelle-Terovan et al. (2015) show for the Netherlands, a history of crime in young adulthood reduces the likelihood of engagement in a relationship of any type (marriage, cohabitation or non-cohabitation). Schoon and Mullin (2016), on the other hand, find the surprising outcome that UK men who have been persistent offenders are more likely to be living with a spouse and child(ren) at age 30 , and that women who have offended only during adolescence are more likely to be in a stable relationship.

Union dissolution is studied as well. We find consistent evidence that engagement in crime increased the risk of separation in the Netherlands (Zoutewelle et al. 2015) and the UK (Besemer, Farrington \& Theobald 2016). Focusing on the timing of offending related to separation, Zoutewelle et al. (2015) find that past offending is not related to the risk of separation in a relationship. However, current offending is related to relationship break-up, but the effects differ by type of crime for men and women (for men only violent offending increases the risk of separation, whereas for women engagement in any offending has this effect). The likelihood of relationship separation is studied also from the perspective of intergenerational effects. In the UK, Besemer, Farrington and Theobald (2016) find that parental separation is not related to a son's separation. However, the likelihood of separation for men is increased by parental offending. Clearly, a son's personal characteristics have a stronger effect on the likelihood to engage in a relationship than parental offending.

All in all, it appears that relationship formation (marriage or other relationships) regularly emerges as negatively influenced by someone's own offending. However, the effect of crime on relationship break-up seems stronger for women, and more related to engagement in violent crime for men. Offending in the family is related to an earlier transition to marriage for both men and women, and a higher likelihood of separation for men (unfortunately no study investigates this effect for females).

Studies on parenthood in this volume have a specific focus on the timing of parenthood, than on the likelihood of becoming a parent. The study of Bijleveld, Liefbroer and Huschek (2016), conducted in the Netherlands on a high-risk sample, finds no effect of juvenile offending on parenthood. However, a different study on the Netherlands (Huschek and Blokland 2015), conducted on a convicted sample (a sample of more serious offenders compared to the other high-risk sample in the Netherlands), shows that high frequency involvement in crime in adolescence and early adulthood leads to an earlier entry into parenthood. Whereas the effects of juvenile offending on the transition to parenthood are consistent across genders, effects of adult crime seem to differ between men and women. Lyngstad and Skardhamar (2015) find that own crime is associated with a faster transition to parenthood for Norwegian men, but not for women. The same effect for men is confirmed by Besemer, Farrington and Theobald (2016) in their study on the UK. Huschek and Blokland (2015) also find that all types of crime frequency are associated with an earlier transition to parenthood, but that this effect is stronger for the most criminally active men. The study of Schoon and Mullin (2016) focuses on the influence of crime on teenage parenthood in the UK and finds that, for men, all types of criminal involvement (adolescent limited, persistent and late onset) increase the risk of teen parenthood, whereas for women only persistent crime predicts 
this outcome. It is interesting that all these studies, conducted on different countries and on different samples (Lyngstad \& Skardhamar 2015 - in Norway on a general population sample, Besemer, Farrington \& Theobald 2016 - in the UK on a high-risk group, Huschek \& Blokland 2015 - in the Netherlands on a convicted individuals sample, and Schoon \& Mullin 2016 - in UK on a general population sample) find relatively similar results. This shows that the effect of crime on the transition to parenthood is a robust one.

Intergenerational effects have been investigated as well, with some contradictory results. Bijleveld, Liefbroer and Huschek (2016) find that, regardless of own offending, Dutch high-risk women delay parenthood if their father and mother have engaged in crime (no effect for men). However, the maternal behavior effect is rather weak and becomes statistically insignificant after controlling for female's own marriage. The study of Lyngstad and Skardhamar (2015) finds no gender differences in Norway and concludes that both men and women experience a faster transition into parenthood if crime takes place in their immediate network (parents and siblings). Similarly, in the UKmen study (Besemer, Farrington \& Theobald 2016) shows that parental crime leads to a younger age of first childbirth.

The crime-family relationship is also investigated in the perspective of cumulated events, specifically as an interaction between union formation and parenthood. In their UK study of men, Besemer, Farrington and Theobald (2016) find that own engagement in crime increases the risk of entry into a shotgun marriage. Huschek and Blokland (2015) show that for Dutch men, crime leads to a faster transition into out-of-wedlock parenthood, but has no effect on childbearing within marriage. However, their study also reveals that a high frequency involvement in property, violent and drug related offenses for men leads to an earlier transition to parenthood within marriage, whereas for women only a high frequency involvement in violent crime speeds up the entry into parenthood. The UK study of Schoon and Mullin (2016) reveals that among the different types of offender groups (adolescent limited, persistent and late onset), only individuals in the persistent crime group are more likely to live with a partner and have children at age 30 (compared to the non-criminal group).

Mortality and injury are studied by van de Weijer, Bijleveld and Huschek (2015) and by van Gaalen (2016). Van de Weijer, Bijleveld and Huschek (2015) investigate whether offending increases the risk of death in a Dutch high-risk sample. Controlling for parental mortality, they find no effect of people's overall offending on their mortality risk. Whereas their results contradict previous findings, the authors argue that their withinindividual analysis approach, which controls for family risk factors is robust and that the relationship observed in previous studies may be spurious. However, when analyzing specific types of crimes, the authors find that drunk driving did increase the risk of death. The question whether this is an effect of the commission of such offences, or the outcome of (years of severe) alcohol abuse remains to be answered. Van Gaalen (2016) studies whether children's mortality risk increases if their parents have offended in the previous year, using a Dutch population sample. Van Gaalen comes to a quite similar conclusion as van de Weijer, Bijleveld and Huschek (2015), in the sense that offending of parents in general does not increase their children's mortality risk, once family risk factors were accounted for. However, if fathers are serious offenders, children's risk of death increases, and it does as well when mothers offend. Van Gaalen also studies the risk of injury and finds that both father's and mother's offending increases the risk of getting 
injured. However, the effects seem to be quite small. Combined, the studies appear to indicate that familial risk factors play a larger role in mortality risk than offending per se. Family deviance, as indicated by paternal serious convictions and maternal convictions, may be associated with exposure of children to risk of accidents and death.

The results of the papers included in this special issue also have implications for our thinking about the theoretical mechanisms that could be at play. First, these studies provide evidence for an intergenerational transmission mechanism (Thornberry et al. 2003). Parental crime and crime in the family network are associated with an earlier transition to marriage, an increased risk of relationship separation, an earlier age of entry into parenthood, a higher risk of injury and a higher mortality risk during childhood. A second mechanism for which evidence is found is cumulative disadvantage (Dannefer 2003). Three aspects need to be mentioned in this context: a) that the likelihood of entering a relationship of any type decreases with each offense committed in the past; $b$ ) that the likelihood of separation increases when more offenses are committed; c) that the most criminally active individuals experience an earlier transition to parenthood. Across different life experiences, all types of crime frequencies speed up the transition to parenthood among non-married individuals (but not among married individuals). In other words, the combination of abstaining from marriage and crime involvement has a strong effect on the likelihood of becoming a parent. A third mechanism on which these studies shed light is labeling (Paternoster \& Iovanni 1989). Whereas no support is found for a labeling effect regarding the engagement in adolescent risky behaviors (these behaviors have no influence on the likelihood or timing of marriage), we find some support for labeling effects in young adulthood (past offending reduces the likelihood to have a relationship). The labeling effect functions differently across genders, as a history of violent offending diminishes the chances of men on the marriage and partnership formation market, whereas women's chances are already reduced if they commit lighter offenses, such as property offenses. Alternatively, one could argue that these effects could be explained by a selection mechanism. For example, individuals with a lower level of self-control might be more likely to engage in crime but also more likely to avoid marriage or divorce. However, the methodological approaches adopted in the studies included in this special issue (e.g. longitudinal designs, within-individual analyses, controls for complex sets of family and individual related factors) allow to largely control for such selection effects.

We hope that this special issue will show the potential of applying a life-course perspective to the study of the interrelatedness of criminal and demographic careers, and will spark future research on these interrelationships, preferably in interdisciplinary teams combining expertise from criminology and demography.

\section{References}

Bersani, B. E., Laub, J. H., \& Nieuwbeerta, P. (2009). Marriage and desistance from crime in the Netherlands: Do gender and socio-historical context matter?. Journal of Quantitative Criminology, 25, 3-24. 
Bijleveld, C., Huschek, D., Liefbroer, A.C. (2016). Parental criminality and entry into parenthood among sons and daughters. Advances in Life Course Research, Doi:10.1016/j.alcr.2016.03.006

Blokland, A. A. J., \& Nieuwbeerta, P. (2005). The effects of life circumstances on longitudinal trajectories of offending. Criminology, 43, 1203-1240.

Dannefer, D. (2003). Cumulative advantage/disadvantage and the life course: Crossfertilizing age and social science theory. Journal of Gerontology: Social Sciences, 58B(6), S327-S337.

Giordano, P. C., Cernkovich, S. A., \& Rudolph, J. L. (2002). Gender, crime, and desistance: Toward a theory of cognitive transformation. American Journal of Sociology, 107, 990-1064.

Huschek, D. \& Bijleveld, C. (2011). Standard and deviant family-life circumstances and offending. Findings for a mid-20s century high-risk cohort. Paper for the Annual Conference of the Dutch Society of Criminology, Leiden, The Netherlands.

Huschek, D., \& Blokland, A. (2015) Crime and parenthood: Age and gender differences in the association between criminal careers and parenthood. Advances in Life Course Research, Doi: http://dx.doi.org/10.1016/j.alcr.2015.09.006

Laub, J. H., Nagin, D. S., \& Sampson, R. J. (1998). Trajectories of change in criminal offending: Good marriages and the desistance process. American Sociological Review, 63, 225-238.

Liefbroer, A. C., \& Billari, F. C. (2010). Bringing norms back in: A theoretical and empirical discussion of their importance for understanding demographic behaviour. Population Space and Place, 16, 287-305.

Lyngstad, T. H., \& Skardhamar, T. (2015). Family formation and crime: What role for the family network? Advances in Life Course Research, Doi: http://dx.doi.org/10.1016/j.alcr.2015.09.007

Monsbakken, C. W., Lyngstad, T. H., \& Skardhamar, T. (2013). Crime and The Transition to Parenthood The Role of Sex and Relationship Context. British Journal of Criminology, 53, 129-148.

Paternoster, R., \& Iovanni, L. (1989). The labeling perspective and delinquency: An elaboration of the theory and an assessment of the evidence. Justice Quarterly, 6, 359-394.

Sampson, R. J., Laub, J. H., \& Wimer, C. (2006). Does marriage reduce crime? A counterfactual approach to within-individual causal effects. Criminology, 44, 465508.

Schoon, I., Mullin, A.J.C. (2016). Crime involvement and family formation: Evidence from the British birth cohort study. Advances in Life Course Research, Doi:10.1016/j.alcr.2016.03.003

Thornberry, T., Freeman-Gallant, A., Lizotte, A., Krohn, M., \& Smith, C. (2003). Linked Lives: The Intergenerational Transmission of AntiSocial Behavior. Journal of Abnormal Child Psychology, 31: 171-184.

Thornberry, T.P., Krohn, M.D., Augustyn, M.B., Buchanan, M., Greenman, S.J. (2015). The impact of adolescent risk behavior on partner relationships. Advances in Life Course Research, Doi: http://dx.doi.org/10.1016/j.alcr.2015.04.002

Van de Weijer, S., Bijleveld, C. \& Huschek, D. (2015). Offending and Mortality. Advances in Life Course Research, Doi: http://dx.doi.org/10.1016/j.alcr.2015.11.004 
Van Gaalen, R. (2016). Parental crime and the safety and survival of small children. Advances in Life Course Research, Doi: 10.1016/j.alcr.2016.03.001

Willekens, F. (1991). Understanding the Interdependence Between Parallel Careers. In J. Siegers, de Jong-Gierveld, J. \& van Imhoff, E. (Eds.), Female Labour Market Behaviour and Fertility (pp. 11-31). Berlin Heidelberg: Springer.

Zoutewelle-Terovan, M., van der Geest, V., Liefbroer, A., \& Bijleveld, C. (2014). Criminality and family formation: Effects of marriage and parenthood on criminal behavior for men and women. Crime \& Delinquency, 60, 1209-1234.

Zoutewelle-Terovan, M., van der Geest, V., Liefbroer, A.C., Bijleveld, C. (2015). The influence of criminal offending on union formation and union dissolution for disadvantaged individuals. Advances in Life Course Research, Doi: http://dx.doi.org/10.1016/j.alcr.2015.08.001 